\title{
Enter the Matrix: Building Creative Industry through Delivering Insights in Comics
}

\author{
Hafiz Aziz Ahmad ${ }^{1,2}$, Alvanov Zpalanzani ${ }^{1,2}$ \& Setiawan Sabana ${ }^{3}$ \\ ${ }^{1}$ Comics \& Sequential Media Research Center, \\ Visual Communication \& Multimedia Research Group, Faculty of Art \& Design, \\ Institut Teknologi Bandung, Jalan Ganesa 10, Bandung 40132, Indonesia \\ ${ }^{2}$ Department of Visual Communication Design, \\ Institute Management of Telkom, Jalan Ganesa 10, Bandung 40257, Indonesia \\ ${ }^{3}$ Art \& Design Research Center, Institut Teknologi Bandung, \\ Jalan Ganesa 10, Bandung 40132, Indonesia \\ Email: hafizsan@yahoo.com
}

\begin{abstract}
Comic is a media which delivers its content through visual sequence. This media has negative preference in Indonesia's community because viewed as mild entertainment for children. Yet in modern society, comics observed and researched as one of media which could penetrate deep within its reader's mind. In re-create cultural insight through comic, the content must encrypt into visual and sequential mode which form a matrix of insight. This matrix will encompasses the effective transformation of cultural content in comic and also other visual media through media linkage strategy. The media linkage strategy is to surround the children's access of information and visual entertainment in order to build certain knowledge and understanding. It's a system that crystallized from global marketing practices of visual media industry over decades. This paper urges to highlight the visual communication design study in creating a matrix of cultural insight in translating cultures of Archipelago and media linkage strategy in order to strengthen cultural understanding among children.
\end{abstract}

Keywords: comics; cultural insight; cultural content; media linkage; visual language.

\section{The Emergence of Comics}

\subsection{Comic Acknowledgement}

Comic is a juxtaposed pictorial and other images in deliberate sequence, intended to convey information and/or to produce an aesthetic response in the viewer [1]. Based on its production process and output, comic divides into two categories. Traditional comic and modern comic. While traditional comic consist of various visual messages placed sequentially in depicting myths, legends, or epic stories of the past in ancient cultures such as Wayang Beber \& Borobudur reliefs [2], Aztec \& Inca mythology [1], or Ukiyo-e from Japan [3];

Received November $27^{\text {th }}, 2009$, Revised October $29^{\text {th }}, 2013$, Accepted for publication November $8^{\text {th }}, 2013$. Copyright (C) 2013 Published by LPPM ITB, ISSN: 1978-3078, DOI: 10.5614/itbj.vad.2013.4.1.1 
Modern comics are visual messages made through sequence of panels, printed [1], and define as sequential art [4].

Since the end of the twentieth century (1980-now), the comics industry in the world is mostly dominated by comics from United States of America, Europe (especially from Belgium, France and Netherland) and Japan with each area developed their own unique approach in character design and storytelling [5]. Comic started to be acknowledged aesthetically in Europe as the ninth medium [6] and several research on comics as a visual communication media have also been carried out, such as by Will Eisner [4], Scott McCloud [1] and Robert C. Harvey [7]. Research on comics as medium popularizing visual language had also been done by Neil Cohn [8] and Tarbani [2]. Furthermore, comic has been accepted as a medium of high literature. Maus, a semibiographical comic about the holocaust tragedy during the World War II by Art Spiegelman had won the Pulitzer award for literature in 1992.

Comic, along with children's picture books, has become a popular mass media with its unique ability to penetrate almost every level of the society with relatively low production cost. Communication which is designed through sequential visual media has enabled the society to get equal information in almost every level of education [3]. Relating to this fact, comics and illustrated books would be an advantage as a medium for educational purpose.

The comics' uniqueness in its ability to carry various content and vast coverage areas is a big potential to deliver information and knowledge related to culture. According to [9], comic features a good layering encryption system that enables comics to teach its reader without the later realizing that he is being taught. Furthermore, comic has been mentioned as an effective medium for cultural penetration [10]. In Indonesia, comics (along with other popular media such as animation and music) contributed a significant role in introducing the Japanese culture to the young generation. Many Indonesian young readers seem to appreciate and even have more understanding toward Japanese traditional culture than Indonesia which has richer and various traditions.

Judging by these phenomena, comic is a potential medium in delivering information and understanding on the culture of Nusantara to the Indonesian society. Comics and illustrated books as part of Indonesia's creative industry also have the big potency to increase the economical input as one of the strategic industry for the future of Indonesia. Through the medium of comics and illustrated books, the process of developing the aesthetics intelligent and business ability could be done simultaneously. 


\subsection{Comic Language}

All media of communication are a by-product of human inability to communicate from mind to mind. Each medium (the term of medium comes from the Latin word meaning middle) serves as a bridge between minds. Media converts thoughts into forms that can be transverse the physical world and be re-converted by one or more senses back into thoughts [1]. Based on visual language studies, comics may have a system to convey its message visually through representative visuals and sequence. Representative visual means visual that employs descriptive meanings through icons without interpretative meanings [2].

Because mainly consist of images in sequential, comics is a medium based on the whole world of visual iconography, a language that used symbol as visual vocabulary in telling stories. The symbol, which called icon, means to any image used to represent a person, place, thing or idea. Icon could be categorized as non-pictorial icons, which has fixed and absolute meaning because they represent invisible ideas, and pictorial Icons, with has fluid and variable meaning, according to appearance.

Pictorial Icons can be put in some sort of order, started from the photographic and realistic pictures that most resembles their real life counterparts. Gradually, through simplification of form, the picture then is more of a cartoon, far further from the real thing. However, even the form of cartoon is far from the real thing, we could respond it as much or more than a realistic image. McCloud defined it as amplification through simplification. Through simplification, the cartoon would present the essential meaning from an object and amplified that meaning in the ways that realistic form could not. This kind of simplification toward pictures and characters toward a purpose would become an effective tool in storytelling in any medium.

Another thing is the universality of cartoon imagery. The more cartoons a face is, the more people it could be said to describe. The human brain's ability to perceived two dots and a line inside a circle as a personification of face is incredible. Even more, we could not avoid ourselves from seeing the face. This because humans are a self centered race, who visualize their selves in many things in this world. That is why through the cartoon (that is the basis of comics), we do not just observe it, but we also become the cartoon itself. We identify ourselves to the cartoon. And this is how comic works.

How to identify the process and the system in conveying information through visual sequence in plane media called comics? In this paper, we named the system to deliver the message in visual sequence and elements of visual 
storytelling as the Matrix of Comics. We may found the matrix of translating the (cultural) content through visual sequence from researching translated Japanese comics which published in Indonesia by Elex Media. Manga, Japanese terminology of comic, developed tremendously in Japan. As one of creative industry, manga contribute as one of the largest revenue for Japan.

There are several Japanese comics that use ancient Japan timeline as story settings and we derived the matrix from it (Figure 1).

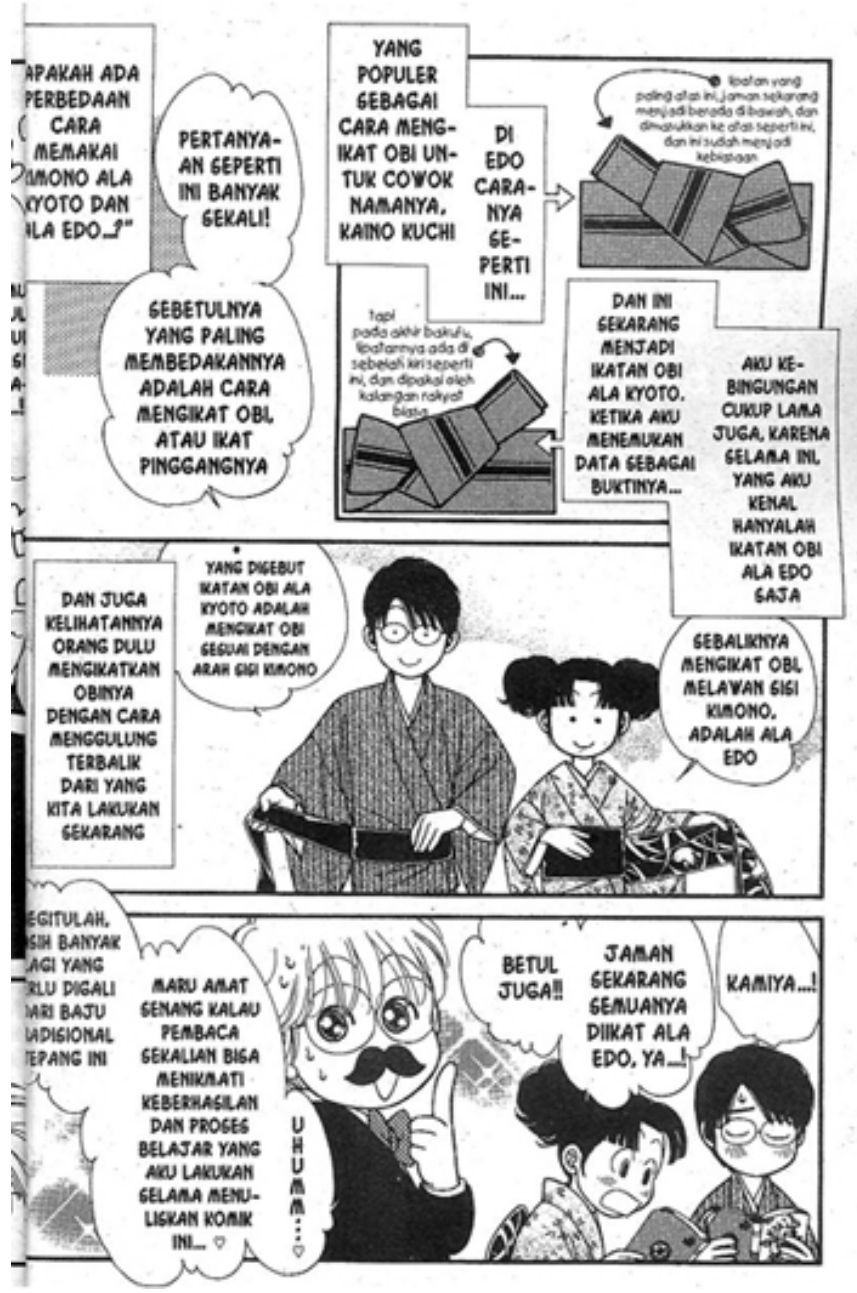

Figure 1 Comic with information regarding particular culture in Japan. Source: TAEKO, Watanabe, Flash of Winds, 2004 [11]. 


\section{Insight in Sequential Art}

\subsection{Insight and Knowledge}

There are slight difference in term of knowledge and insight. The 'knowledge' term can be defined as a body of facts learned by study or experience or understanding and information gained by being educated. On the other side, the term of 'insight' refers to clear perception and understanding of inner qualities of facts or things.

Insight and knowledge highly differentiated in term of delivering the message. Knowledge is general term of information that being taught or the receiver act passively while insight may be personal, sudden understanding where the receiver actively search the facts. Insight depends on how the narrator delivers the information in similar tone and nuance with its receiver.

Comic is a media where the readers are actively follows the story through visual sequence by turning the comic pages. Also, comic is a media of sharing interpretation between the author and the reader.

\subsection{Information through Visual Sequence}

As a visual based medium, comics could be used to translate or transform textual information (descriptive) into visual form which is more representative. Comics as a medium of information began from the beginning of the development of modern comics, especially in Europe and Japan. Comics artists from Europe and Japan tend to show and share important information regarding their story, in order to give the reader more complete experience and knowledge. It is common to learn something related to history, way of life or other related fact in particular story with specific setting and background.

According to [9], there are two ways to transfer information in comics: by informing through interaction and by informing through visualization. Most information in comics is transferred through character interaction which has three variants. First is to transmit information through dialog, using verbal conversation between characters interaction in the story. Second is through narrative, conveying information verbally through the use of narrated text balloon. The third is through communication boxes, in which the information is delivered using additional column.

Informing through visualization also consists of two methods. The first is the diagrammatic visualization in which the information is processed using diagram or sequences in several panels illustratively. The second is the representative 
visualization, in which the process of informing is conveyed through visual detail in background setting and property.

In building the insight matrix in a comic, we must define the elements of the matrix. The number or column and row in a matrix depend on the number of variables of a comic. This system is similar with Tsukamoto's character matrix [12]. Through the character matrix, we could elaborate abundance exploration of a character's visualization in comics, animations, and games.

\section{$3 \quad$ The Matrix of Comic}

The variables of comic matrix are grouped into four categories, storytelling elements, comic structure elements, visual elements and verbal elements. These are the brief description of each element.

\subsection{Storytelling Elements}

Storytelling elements consist of characters, storyline, and setting. Those are the most basic elements in every story production especially in comic.

\section{Characters and characterization}

Character and characterization is very important element in storytelling. It is the subject of a story that controls the flow of information. The characterization is the process of personality building of characters in the story. How they appeal the readers mainly because of character's charm. The recent trend of personality of comic character usually timid, shy, naive, and even looks silly in the beginning but naturally become cleverer in the process. The main characters usually supported by several sidekicks or are supporting characters that lecture, trains, and even teach the main characters to become more and more skillful. Therefore, the supporting characters are exceptionally smart or strong but less creative than the main characters. Either the supporting characters are protagonist or antagonist, they are the provider for any information that the main character needed.

\section{Storyline}

Comic's theme may vary, but there is a common pattern in such comics that intend to build insight of the readers. It is a plot that the main character must learn from his/her mistakes or obstacles that needs his/her understanding on the subject to overcome. That information will be provided by his/her allies, rivals, or even his/her enemies. Sometimes, the scientific experiment conducted by the main character may give the similar results. 


\section{Time or place setting}

Time of place setting gives high significance to create story realism and earn high trust-ability from readers. Although the readers aware that they are reading fiction literature, they perceive the setting of time and place from author's vivid observation on history, culture, and lifestyle as realistic visual construction of setting. Therefore, when the author spilled some facts that astound the readers, the readers will believe it.

But the question is, how do the readers know about the effort of the authors? In Japan, comic authors cleverly inform the readers about his/her research for their comics through additional pages at the end of the comics. They share their obstacles, findings, or anything interesting stories they could share to make the readers know the creative process

\subsection{Comic Structure Elements}

Comic structure elements usually consist of several interdependent parts that are assembled into a greater, inter connected whole. In the linear story such as in comics, the story structure usually consists of three parts which is known as the three acts structure, with Act One being the beginning, Act Two being the middle and Act Three being the end.

In Act One, a catalyst begins the action an event that gets the story going and orients the audience to genre, context and story. Act Two develops and explores conflicts, relationships and themes, using action and events to move the story forward. Act Three is the consequence of the work of Act One and Act Two, paying off all the development, strategizing and struggle that went on through out Acts One and Two [13] .

The basic of the Three Acts Structure could be developed into several other structures. Dwi Koen, a comic artist from Indonesia divided the comic structure into five acts: Introduction, 1st Conflict, 2nd Conflict, Climax and Anti Climax. Introduction begins by informing about the main characters (protagonist) and background story which would affect the entire story later on. 1st Conflict presents the supporting roles which could the companion of the main characters or even the antagonist characters. 2nd Conflict begins the conflict between the protagonist and the antagonist. Climax shows the escalating conflict between the two that end up in a big showdown. Anti Climax brings the resolution of the conflict and ends the whole story [14].

With all the various combination and development of comic structure, the most basic structure would consist of three acts: Introduction (Beginning), Conflict (Middle), and Resolution (Ending). In several works from Japan, the comic 
artists even added the addendum part, to give additional information regarding the story and cultural background. This addendum could be integrated seamlessly into the story or act as a stand alone story.

\subsection{Visual Elements}

The third variable in the comic matrix is the visual elements that describe the sequence structure in comic that consist of image composition, panel and its composition in the page, closure, word balloon, narrated balloon, typography and colors. Tabrani summarized these visual elements as inner grammar [2]. However due to exploration by many comic artists, the variable in these visual structure would be always growing.

The main point in arranging inner grammar is to put these visual elements to work in synch with the principles of clarity and communication to make the audience understand our intention and purpose.

The basic principle in transferring information through comic is to optimize and to share information between comic artist and the reader.

\subsection{Verbal Elements}

Comic also features combination of words and pictures and had tremendous influence on its growth. The combination enables the portrayal of huge range of human experiences. According to McCloud [1], there are seven combinations between words and picture, which consist of:

1. Word specific, where pictures illustrate, but don't significantly add to a largely complete text.

2. Picture specific, where words do little more than add a soundtrack to a visually told sequence.

3. Duo-specific, where words and pictures send essentially the same message.

4. Additive, where words amplify or elaborate on an image or vice versa.

5. Parallel, where words and pictures seem to follow very different courses without intersecting.

6. Montage, where words are treated as integral parts of the picture.

7. Interdependent, where words and pictures go hand in hand to convey an idea that neither could convey alone.

\section{Conclusions}

Comic has developed a system of transferring information which could be applied not only to boost the reader's knowledge but also to strengthen reader's 
believe of the seriousness and the truthfulness of the information acquired by the comic artists.

The system of transferring information through visual sequence could be concise comic matrix that consists of into four main categories: storytelling elements, comic structure elements, visual elements and verbal elements. The implementation from comic matrix is very experimental and varied, de-pending on the style and preference of each comic artist. However, the important points from the comic matrix are:

1. Observation and information tracking through scientific method;

2. The translation process of textual information into visual and sequential information through illustrative way.

3. Identification of information within comic could be structured hierarchically (from the easiest to identify until the most difficult one).

4. The desire to share information that had been acquired by the artists had strengthened the emotional bond between the artist and the reader.

5. The challenge for Indonesian comic artist that require them to learn and obtain information through scientific method, and then to present them to audience intelligently.

This opens a wide possibility to use comic to inform and integrated cultural content within, especially since Indonesia is rich of culture and tradition.

This research is a preliminary stage and would need further comparative study and research to get more comprehensive result in order to strengthen the findings from previous researches.

\section{References}

[1] Mccloud, S. 1993. Understanding Comics: The Invisible Art, New York: Harper Collins, Inc.

[2] Tabrani, P. 2005. Bahasa Rupa, Bandung, Penerbit Kelir.

[3] Schodt, F.L. 1996. Dreamland Japan: Writings on Modern Komik, Stone Bridge Press.

[4] Eisner, W. 1985. Comics and Sequential Art, Florida: Poorhouse Press.

[5] Ahmad, H.A., Zpalanzani, Alvanov \& Maulana, Beny. 2005. Keliling Komik Dunia, Jakarta: Elex Media Komputindo.

[6] Screech, M. 2005. Masters of the Ninth Art: Bandes Dessinees and Franco-Belgian Identity, Liverpool University Press - Contemporary French \& Francophone Cultures.

[7] Harvey, R.C. 1996. The Art of the Comic Book: An Aesthetic History, Jackson: University Press of Mississippi, 1996. 
[8] Cohn, N. 2003. Early Writings on Visual Language, Carlsbad CA, Emaki Productions.

[9] Zpalanzani, A. \& Piliang, Y.A. 2009. Framing, Pencitraan dan Panduan Grafis dalam Image Sekuensial pada Komik Perempuan, Wimba, 1(2), FSRD Institut Teknologi Bandung.

[10] Ahmad, H. \& Zpalanzani, A. 2009. Manga: Invisible Cultural 'Imperialism' through Popular Medium, Wimba, 1(1), FSRD Institut Teknologi Bandung.

[11] Taeko, W. 2004. Flash of Wind, 16, Jakarta, Penerbit Elex Media Komputindo.

[12] Tsukamoto, H. 2006. Manga Matrix: Create Unique Characters Using The Japanese Matrix System, Collin Design.

[13] Miller, C.H. 2004. Digital Storytelling, Oxford, Focal Press.

[14] Koendoro, D. 2007. Yuk, Bikin Komik, Bandung, Dar Mizan. 